\title{
Editing of a tRNA anticodon in marsupial mitochondria changes its codon recognition
}

\author{
Axel Janke and Svante Pääbo* \\ Institute of Zoology, Luisenstrasse 14, University of Munich, W-8000 Munich 2, Germany
}

Received February 8, 1993; Revised and Accepted March 2, 1993

\begin{abstract}
RNA editing has been described for organellar genes of protozoa and plants as well as In three cases for nuclear transclpts of mammals. The mitochondrlal tRNA for aspartic acld is encoded in the mitochondrial genome of marsuplals with the antlcodon GCC. However, cDNA from the gene product revealed that the second nucleotide of the anticodon of the tRNA is posttranscriptlonally changed to be recognized as an uridine residue. This restores the coding property of the tRNA. Direct sequencing as well as clones of the amplified cDNA Indlcated that about $50 \%$ of the cellular pool of pre-tRNA molecules for aspartic acld is edited. Thus, RNA editing occurs in mammallan mitochondria and can affect the anticodons of tRNAs.
\end{abstract}

\section{INTRODUCTION}

RNA editing is a process by which RNA is post-transciptionally changed such that new genetic information not encoded in the DNA is created. In mitochondria of protozoa RNA editing results in the insertion and deletion of uridine residues (1) and thus extensive modifications of many mRNAs (2). In plant mitochondria, as well as to a lesser extent in chloroplasts, RNA editing most commonly substitutes uridine residues for encoded cytidine residues, sometimes changing more than ten percent of the codons in the mRNA. Infrequently, also $U$ to $C$ editing occurs (3-5). In mammals, only three cases of RNA editing have been described. The transcript of the human apolipoprotein $B$ gene is edited in liver such that a glutamine codon (CAA) is changed to a stop codon (UAA) (6). In the mRNA encoding a glutamategated ion channel in mice a glutamine (CAG) codon is edited to an arginine (CGG) codon, resulting in two channels with slightly different functional properties ( $T$ ). Finally, in the rat, a nuclear-encoded tRNA is modified at two nucleotide residues upstream of the anticodon by a process that changes cytidine to uridine residues. However, this does not change the coding specificity of the tRNA (8). Here we demonstrate one case of RNA editing in marsupials that changes the codon recognition of a mitochondrial tRNA by changing the sequence of its anticodon.

\section{MATERIALS AND METHODS}

DNA preparation, enzymatic amplification and sequence determination

DNA was prepared from tissues by proteinase $\mathbf{K}$ digestion followed by phenol/chloroform extraction and enzymatically amplified as described (9). The primers used were L06820 ( $5^{\prime}$-AGTATTTATTATTTGAGAAGC-3') and H07168 (5'-CTGATCAGAAATACAATTAT-3'). The temperature profile for 40 cycles of PCR was $40 \mathrm{sec}$ at $92^{\circ} \mathrm{C}, 1 \mathrm{~min}$ at $55^{\circ} \mathrm{C}$ and $1 \mathrm{~min}$ at $72^{\circ} \mathrm{C}$. If nonspecific bands appeared, purification was performed in $2 \%$ low-melting agarose gels from which the appropriate bands were cut out and reamplified as above. The DNA was purified with GeneClean (Dianova) and directly sequenced (10) by the dideoxy chain termination method.

RNA preparation, cDNA synthesis and molecular cloning Total RNA was isolated from frozen liver of Didelphis vinginiana by a guanidinium thiocyanate method (11). $2 \mu \mathrm{g}$ of RNA were incubated in $50 \mathrm{mM}$ TrisCl pH 8.3, $20 \mathrm{mM} \mathrm{KCl}, 10 \mathrm{mM} \mathrm{MgCl}{ }_{2}$ with 1U of RNAase Block (Stratagene) and 10U of RNase free DNase at $37^{\circ} \mathrm{C}$ for $15 \mathrm{~min}$. The DNAase was inactivated by incubating the reaction mixture for $2 \mathrm{~min}$ at $100^{\circ} \mathrm{C} .5 \mathrm{mM} \mathrm{DTT}$, $0.25 \mathrm{mM}$ dNTPs, $1 \mathrm{mM}$ primer H07061 (5'AAGATATATAGGAGTTAAA-3') (final concentrations), 27 U AMV-RT (Stratagene) were added and the mixture was incubated for 45 $\min$ at $42^{\circ} \mathrm{C}$. The reaction was terminated by heating for $3 \mathrm{~min}$ at $100^{\circ} \mathrm{C}$. To $25 \mu \mathrm{l}$ of the reaction mixture, $75 \mu \mathrm{l} \mathrm{H}_{2} \mathrm{O}$ were added. $2 \mu \mathrm{l}$ were used for an amplification of 40 cycles with primers L07030 (5'-AAGATATTAGTAAAATTCA-3') and H07061. In control experiments, the RNA was additionally treated with RNase $(0.1 \mathrm{mg} / \mathrm{ml}$ final concentration) for $15 \mathrm{~min}$ at $37^{\circ} \mathrm{C}$ prior to cDNA synthesis. From this control no DNA could be amplified. The DNA from Fig. 2 was sequenced as described with an $\mathrm{P}^{32}$-endlabelled primer $\mathrm{H} 07066$ (5'-AAGATATATAGGAG-3') and the fragments were separated on a $12 \%$ polyacrylamide sequencing gel. The PCR products were cloned by annealing to a T-tailed vector (Invitrogene). Colonies were screened with an end-labeled internal oligonucleotide L07043 (5'-ATTCATTACATAACTTTG-3'). More than 90\% of the $\beta$-galactosidase-negative colonies contained tRNA ${ }^{\text {Asp }}$ inserts.

\footnotetext{
* To whom correspondence should be addressed
} 


\begin{tabular}{|c|c|c|}
\hline & D-loop & AC-loop \\
\hline his & TAA $\overline{\text { AATTCA }}$ & GTTTAACTCCTATATATCTTA \\
\hline & - & \\
\hline $\begin{array}{l}\text { letachirus } \\
\text { halanger }\end{array}$ & $\begin{array}{l}\ldots \ldots \ldots \text { C. A. } \\
\ldots \ldots \ldots \text { T. AAA. } \\
\ldots \ldots \ldots \text { T. }\end{array}$ & . \\
\hline
\end{tabular}

Figure 1. MtDNA sequences for the tRNAAsp from five marsupials. Dots indicate sequence identity with opossum DNA, dashes indicate deletions. Loop structures are overlined and the dihydrouridine (D), anticodon (AC) and pseudouridine (T) loops indicated. The anticodon is written in bold letters.

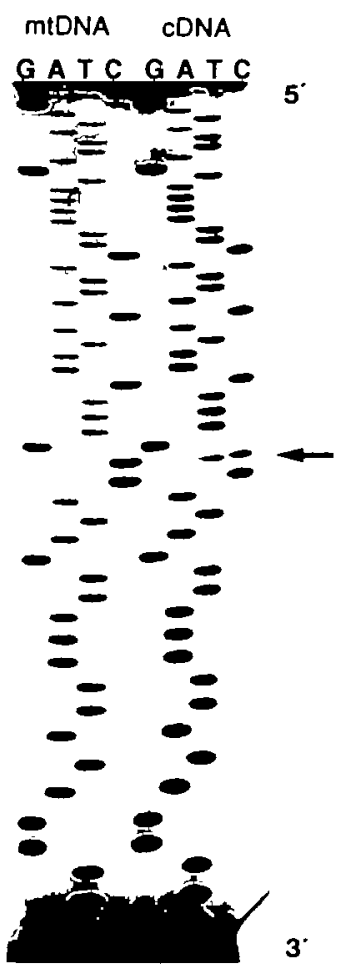

Figure 2. Directly determined sequences of tRNAAsp cDNA (right lanes) and the mitochondrial gene (left lanes). The 5' end of the gene is at the top of the gel. The arrow indicates the second position of the anticodon.

Table I. Number of clones of cDNA and mtDNA, which carry the anticodon GTC and GCC.

\begin{tabular}{llc}
\hline anticodon & cDNA & mtDNA \\
\hline GTC & 16 & 0 \\
GCC & 13 & 12 \\
\hline
\end{tabular}

\section{RESULTS AND DISCUSSION}

In the course of sequencing the mitochondrial (mt) DNA of the North American opossum (Didelphis virginiana, Marsupialia) we found a tRNA gene with the anticodon GCC located at the position in the genome where, in other vertebrates, the tRNA for aspartic acid (tRNA Asp, anticodon GUC) is found. An anticodon GCC would recognize two of the glycine codons (GGY). Since some tRNA genes of marsupials are known to be rearranged when compared to other vertebrates (12), we sequenced the entire opossum mitochondrial genome (data not shown) but failed to find any other tRNA gene which would code for aspartic acid. Furthermore, at the position where other vertebrates have a gene for tRNA ${ }^{\text {Gly }}$, the opossum has a gene with the expected anticodon (TCC). Also, at positions in the protein-coding genes where aspartic acid and glycine are conserved among mammals, the opossum utilizes the expected codons for these two amino acids.

To explore the possibility that the sequence encoding the putative tRNA(GCC) is a pseudogene, we compared its sequence to vertebrate tRNA Asp sequences. The opossum tRNA(GCC) gene exhibits strong conservation in primary as well as inferred secondary structure (not shown). We furthermore sequenced the homologous region of one New Guinean and three South American marsupials. Fig. 1 shows that substitutions are confined to non-conserved regions of the D-loop and T-loop and that all tRNA genes at this location in the mitochondrial genome of these marsupials have GCC as an anticodon rather than the expected GTC. Thus, the tRNA(GCC) gene is conserved among marsupials and evolves as a functional tRNA gene.

To determine the sequence of the gene product of the tRNA(GCC) gene, total RNA was extracted from opossum liver. After treatment with RNase-free DNase, cDNA was synthesized. In control experiments, the RNA was in addition treated with RNase to remove any polynucleotides that could serve as a template for the reverse transcriptase or the Taq polymerase. To eliminate the possibility of PCR and/or sequencing artifacts specific to the second anticodon position of the tRNA(GCC) sequence, the tRNA(GCC) gene from highly purified opossum mtDNA diluted to less than 1000 molecules per tube was amplified and sequenced in parallel. Sequences of the cDNAs and genomic DNA were directly determined from the PCR products (Fig. 2). The cDNA shows the presence of thymidine as well as cytidine residues at the second position of the anticodon whereas the genomic DNA shows exclusively a cytidine residue. All other positions carry only one base and are unambiguously identical between the cDNA and the genomic sequence. To further determine the relative amounts of tRNA(GCC) and tRNA(GTC) in the amplification products, these were cloned. Sixteen of 29 cDNA clones carried a $T$ in the second anticodon position. Thus, about $55 \%$ of the tRNA Asp clones have the expected anticodon (GTC). All clones obtained by amplification of mitochondrial DNA carried a C (Table 1). We conclude that this tRNA is modified by an RNA editing mechanism which generates the appropriate anticodon subsequent to the transcription of the gene.

The first position in the anticodon of tRNA ${ }^{\text {Asp }}$ is known to be modified to contain queuosine in prokaryotes as well as eukaryotes $(13,14)$. Since queuosine is preferentially incorporated into mature tRNAs and most likely impairs reverse transcription, we presume that reverse transcription occurs predominantly with unmodified pre-tRNA ${ }^{A s p}$ and that the $1: 1$ ratio of edited to 
unedited tRNA ${ }^{A s p}$ reflects the this ratio in the pool of pretRNA ${ }^{A s p}$. This would explain the unexpectedly high proportion of unedited tRNA, which, if present in such high quantities in the total tRNA pool, would impair translational fidelity in the mitochondria.

In one case in plants, the first position in the anticodon of a mitochondrial tRNA ${ }^{\text {Ile }}$ has been shown to be posttranscriptionally converted from a cytidine to a lysidine-like residue which will base pair with adenosine rather than guanosine residues (15). It is highly unlikely that such a modification is involved in the marsupial tRNA ${ }^{\text {Asp }}$ since reverse transcriptase might not be able to transcribe the hypermodified lysidine residue. Furthermore, with one exception (16), no modifications of bases in the second position of anticodons have been described.

Recently, editing of several nucleotide residues in the acceptor stem of a tRNA in Acanthamoeba was described (17). The tRNA for aspartic acid described here is the first case of RNA editing in mammalian mitochondria and the first case in animals where the anticodon of a tRNA is changed in such a process. The fact that editing of this mitochondrial tRNA is conserved among marsupials and affects a component essential to the translational machinery of the mitochondria raises the possibility that RNA editing is common to all eukaryotic organisms. It will be central to the understanding of the origin of RNA editing to resolve the mechanism by which it occurs in different groups of organisms. A search of the opossum mitochondrial genome with an algorithm designed to find guide RNAs (modified from ref. 18) failed to yield any indication of sequences potentially encoding such molecules. Further work will be needed to clarify if the tRNA editing in marsupial mitochondria utilizes a deamination pathway similar to the editing of the mRNA for apolipoprotein B in the nucleus of human cells (19).

\section{ACKNOWLEDGMENTS}

We thank G.Feldmaier-Fuchs for expert technical assistance, W.K.Thomas for opossum tissue and mtDNA preparation, A.von Haeseler for help with the search for guide RNAs, M.Höss, A.Brennicke, E.M.Prager and anonymous reviewers for help and comments on the manuscript, and the Genzentrum, München for financial support.

\section{REFERENCES}

1. Benne,R., Van Den Burg,J., Brakenhoff,J.P.J., Sloof,P., Van Boom,J.H., Tromp,M.C. (1986) Cell, 46, 819-826.

2. Simpson,L. (1990) Science, 250,512-513.

3. Walbot, V. (1991) Trends Genet., 7, 37-39.

4. Mulligan, M.R. (1991) The Plant Cell, 3, 327-330.

5. Bonmard,G., Gualberto,J.M., Lamattina,L. and Grienenberger,J.M. (1992) Crit. Rev. in Plant Sci., 10, 503-524.

6. Chen,S.-H., Habib,G., Yang,C-Y, Gu,Z-W, Lee,BR., Weng,S-A, Silberman,S.R., Cai,S-J., Deslypere,J.P., Rossenew,M., Gotto,A.M. Jr.,Li,W-H. and Chan,L. (1987) Science, 238, 363-366.

7. Sommer,B., Köhler,M., Sprengel,R. and Seeburg,P.H. (1991) Cell, 67, $11-19$.

8. Beier,H., Lee,M.C., Sekrya,T., Kuchino, Y. and Nishimura,S. (1992) Nucleic Acids Res., 20, $2679-2683$

9. Thomas, R.H., Schaffiner,W., Wilson,A.C. and Pagabo,S. (1989) Nature 340, $465-467$.

10. Bactmann,B., Lüke,W., Hunsmann, G. (1990) Nucleic Acids Res., 18, 1309.

11. Chomczynski,P. and Sacchi,N. (1987) Anal. Biochem., 162, 156-159.

12. Päabo,S., Thomes, W.K., Whitfield,K.M., Kumazawa, Y. and Wilson,A.C. (1991) J. Mol. Erol., 33, 426-430.

13. Okada,N., Noguchi,S., Kasai,H., Shindo-Okada,N., Ohgi,T., Coto, T., and Nishimura,S. (1979) J. Biol. Chem., 254, 3067-3073.
14. Shindo-Okada,N., Okada,N., Ohgi,T., Goto,T., and Nishimura,S. (1980) Biochem. 19, 395400.

15. Weber,F., Dietrich,A., Weil, J-H. and Martchal-Drouard,L. (1990) Nucleic Acids Res. 18, $5027-5030$.

16. Sprinzl,M., Harmann,T., Weber,J., Blank,J., Zeidler,R. (1989) Nucleic Acids Res. Suppl. 17, r1-r172.

17. Lomergan, K.M., and Gray, M.W. (1993) Science 259, 812-81816.

18. von Haeseler,A., Blum,B., Simpson,L., Sturm,N. and Waterman,M.S. (1992) Nucleic Acids Res., 20, 2717-2724.

19. Hodges,P.E., Navaramam,N., GreeveJ.C. and Soot, J., (1991) Nucleic Acids Res., 19, 1197-1201. 
